\title{
Assessing the Effects of Atmospheric Properties on Energy Commodity Storage and Distribution: Focus on Correlation with Temperature and Wind Variations
}

\author{
Stephen Chijioke Nwanya ${ }^{1}$ and Sunday Olayinka Oyedepo ${ }^{2}$ \\ 1. Department of Mechanical Engineering, University of Nigeria, Nsukka, 410000, Nigeria \\ 2. Department of Mechanical Engineering, Covenant University, Ota, P.M.B. 1023, Nigeria
}

\begin{abstract}
Gasoline vapour emission is an insidious topical air pollution and hazardous health issue underestimated at both storage and utilization levels. Since gasoline station is one public built environment found in every locality, the problem of unguarded vapour emission through this facility needs serious attention. This study measures the close relationship between the emission rate and the ambient properties with specific objectives including evaluating operational emission level and determining the correlation coefficient. Field measurements of evaporated quantities were conducted at selected station in Enugu State. For the random variation in emission quantity, the wheel spun approach was used to obtain all round mean value per month. Also, meteorological records of Nsukka municipal city for the period under consideration were obtained and analyzed for possible relationship by calculation of coefficient of correlation. The findings from this study suggest that gasoline evaporation is strongly correlated with ambient temperature and wind speed variations, respectively. Thus, high concentration of emitted gasoline on a hot day constitutes a potential thermal mass, high in embodied energy and if excited by light wind speed, can flow many distances away from the station. This insightful information on the emission will be useful to environmentalist and decision makers and has potential to bring about policy changes within the industry.
\end{abstract}

Key words: Gasoline emission, refueling station, air pollution, correlation, thermodynamic properties.

\section{Introduction}

Distribution and storage of an energy commodity are important handling practices required for optimal customer satisfaction by bringing the commodity safely within reach. Energy commodity refers to a derived product from either coal, crude oil or natural gas. Crude oil derivatives are products of interest in this study and their major distribution and storage facilities include pipeline system, depot, tank farm, truck and service station. Investing in any of these facilities can be by government and private option, and the chosen size is a function of available capital. Among these facilities, the service station plays critical role in the final stage of product delivery to end customers. It has witnessed largest number of capital

Corresponding author: S. C. Nwanya, Ph.D., Snr. Lecturer, research fields: industrial engineering \& management: investors by individual participation in the Nigerian energy sector. While the station stores and dispenses liquid energy products such as gasoline, diesel or kerosene product, product vapour emission occurs and this is an insidious occupational hazard associated with energy business. The gasoline flow from the underground tank through the nozzle to a vehicle tank creates a thermodynamic system as it escapes into the air and interacts with the environment. The vapour emission occurs because of evaporative tendency of the liquid and this can be measured through Reid vapour pressure (RVP). This study focuses on the connection of some atmospheric thermodynamic properties with emission of gasoline popularly known as premium motor spirit (PMS). The interaction between gasoline and the air presents a loop of positive and negative flows. The positive half involves human activity in the form of mobility leading to value-added benefits, while 
the negative half is a waste which leads to pollution. At service station level, this interaction strongly evolves during delivery of fuel to customers and it comes with both financial and environmental costs: a tangible cost that a customer looses from the quantity purchased and an intangible cost for the corresponding gasoline vapour emissions. Often, public focus tends to be on the tangible cost without consideration for the consequences of intangible cost on the environment. The interest of this study is in the latter cost because atmospheric contribution to its negative effect is currently underestimated. Hence, the gasoline emission from nozzles during station operation and the influence of ambient variables on the leakage are the objects of this paper.

In the context of the study, gasoline vapour emission refers to an integral fraction of this liquid energy commodity that seeps away from the container or nozzle (handling loss) into the environment (biosphere) during retail to end customers and this portends serious risk/danger to human life and property, if uncontrolled. The phenomenon is a thermodynamic problem with open source without a sink for appropriate diffusion. The rates of gasoline emission and end customers demands are intertwined. And while gasoline demand grows with number of filling stations increment in every locality, the insidious topical air pollution and hazardous health effects are significantly high. The fraction of gasoline lost due to evaporation hinders effort to maintain an effective inventory system of petroleum products because of inability of gasoline vendors to account for them. Apart from the environment, operations of gasoline stations either during station tank filling or vehicle refueling impact three human populations, namely those occupationally employed, customers engaging in vehicle refueling; as well as those residing, attending school, or working near the refueling station [1]. Due to rising number of filling stations and size of population residing in the city as well as visible indicators of climate change, correlation analysis of ambient variables' link with gasoline vapour emission becomes necessary so that proper strategies can be formulated for pollution control and minimizing environmental and health effects. This is a serious concern because of the indiscriminate location of filling station in developing country like Nigeria.

For this study, the whole action being considered happens at the filling station between the vehicle tank mouth and dispenser pump nozzle. Many factors contribute to interlined behaviour of gasoline emission and its end customer's demands including human error and atmospheric variables. In this regard, the motivation of present study is to explore the contributions of thermodynamic parameters (ambient temperature and wind velocity) to gasoline vapour emission at service station level.

A survey of literature on petroleum products distribution and storage facilities including gasoline demonstrates that various authors have recognized the benefits of these products to the economy [2, 3]. Onyeizugbe et al. [4] conducted a study, anchored on the central place theory, against the indiscriminate location of filling stations in Nigeria. The study identified a significant relationship between the location and service sustainability of selected petrol stations. A similar study was undertaken by Mshelia et al. [5] and Ogunkoya [6], respectively. The findings revealed that the guidelines for sitting petrol stations have not been adhered by most of the petrol dealers thereby posing serious hazards on residents in close proximity to them, even though, some of these petrol stations were located much earlier than the residential houses. Ogunkoya [6] suggested urgent need for renewed enforcement of such controls and regulations if the nation is to avert mass mortality in the near future. However, very few articles have reported the seepage of the products either at distribution and storage or combustion end points. The product emissions as a result of distribution pipeline accidents have been considered by Nwanya et al. [7] and Belvederesi et al. [8]. Although, those reported incidents involved 
petroleum products on transit, the major green house gas released in the process is methane gas. Hilpert et al. [1] raised the issue of health concerns linked to chronic hydrocarbon releases at gas stations (including both liquid spills and vapor losses), their contributions to human exposures and potential health risks, and factors that influence the adoption of suitable pollution prevention technology. With this view, gasoline evaporation has been termed a pollution factor [9]. However, the article focused on the amount of gasoline that evaporates from a car's fuel system when the vehicle is being used. Abdelmajeed et al. [10] have evaluated the evaporation loss of gasoline from internal floating roof storage tank and expressed deep concern about the lost revenue that would have accrued from it as well the hazards associated to the losses. Similarly, Hoek [11] enumerated different methods for assessing long-term exposures to outdoor air pollutants including geographic information systems (GIS). In summary, findings from the reviewed literature indicate that evaporation of petroleum products during end customer delivery is an inevitable problem which has not received adequate attention. Also, evaporation of gasoline from fuel distribution or storage systems can significantly predispose a host environment to serious danger. The continued negligence of this problem, no matter the intangible quantity, reflects the attitude of low premium on safe work environment. However, to the best knowledge of the authors, no study has been done on correlation analysis of gasoline emission with thermodynamic parameters within the service station.

The aim of this study is to measure the closeness of the relationship between the ambient thermodynamic properties (temperature, wind velocity, pressure) and vapour emission values with a view to conserve the environment. The specific objectives include evaluating gasoline emissions at service station; determining if relationship exists between the emitted values and the defined ambient variables; and determine the correlation coefficient. The investigation is significant in view of the air pollution and consequent climate change implications of emission to the environment.

\section{Methodology}

A case study service station was chosen within Nsukka metropolitan city. The proximity of a meteorological centre and volume of gasoline sales were considered in the selection of a station. A field measurement was conducted on the station's daily gasoline delivery to end customers for the study duration of twelve months. The readings obtained cut across the major two seasons, dry and rainy seasons of the year in varying quantities. Material balance analysis of the daily inventory data was conducted to reveal evaporation losses. For the random variations in emission quantity, the wheel spun approach was used to obtain an all round mean emission value per month. Using the principle of wheel spun, where it stops determining the random emission variable. As long as the spinning wheel is random, the true emissions with the number of frequencies are obtained. Corresponding meteorological records of outdoor dry bulb temperature, wind velocity and relative humidity were evaluated for possible relationship between gasoline vapour emission and ambient parameters. A simple correlation analysis method was carried out and a regression model was used to tie the relationship together.

\subsection{Calculations}

The material flows include stock on-hand, opening stock, sales, closing stock, and replenishment stocks. The material balance was applied by monitoring stock on-hand for each daily transaction. Daily opening stock, sales, closing stock, and supplies records were obtained through a field measurement, then processed and analyzed into evaporated quantity data. The measurements of daily opening stock and closing stock were taken using calibrated dipping stick inserted into the tank, while sales and evaporated quantities were arithmetically obtained from the measurements by the 
station supervisor. The volume of the product is indicated on the calibrated dipping stick (CDS). Therefore, whenever there is a supply, opening stock for the next day becomes closing stock plus supply else opening stock for the next day becomes closing stock of the previous day.

To obtain closing stock, CDS was dipped into the underground tank and the volume (quantity) of the product left after sales for each day was read. The sales for the day were obtained by reading the indicator on the fuel (petrol) pump per day. The evaporated quantity was obtained by adding all sales and closing stock together, and then subtracting the sum from the opening stock, the difference is the evaporated quantity. The monthly emissions $(X)$ data were random and recorded in such a way to use the medium value flow within an interval as average random flow. The average value obtained based on the wheel spun approach is expressed in Eq. (1).

$$
X=\sum_{i=1}^{n} f_{i} P_{i}
$$

where $f_{\mathrm{i}}=$ frequency of occurrence, $n=$ sample size and $p_{\mathrm{i}}=$ daily emission.

A mathematical equation was developed for the association between two numerical variables for the data representing emission and ambient values. The least square line that gives the best fit to the set of data points $\left(X_{1}, Y_{1}\right),\left(X_{2}, Y_{2}\right), \ldots\left(X_{n}, Y_{n}\right)$ has $m$ and $y$-intercept $b$ that satisfy Eqs. (2) and (3).

$$
\begin{gathered}
n b+\left(\sum x\right) m=\sum y \\
\left(\sum x\right) b+\left(\sum x^{2}\right) m=\sum x y
\end{gathered}
$$

By substitution of parameters:

$$
\begin{gathered}
m=\frac{n \sum x y-\left(\sum x\right)\left(\sum y\right)}{n\left(\sum x^{2}-\left(\sum x\right)^{2}\right)} \\
b=\frac{\sum y-m\left(\sum x\right)}{n}
\end{gathered}
$$

To determine whether a relationship exists between $X$ and $Y$ variables, the calculation of the correlation coefficient is expressed as in Eq. (5).

$$
r=\frac{\sum_{i=1}^{n}\left(X_{i}-\bar{X}\right)\left(Y_{i}-\bar{Y}\right)}{\sqrt{\sum_{i=1}^{n}\left(X_{i}-\bar{X}\right)^{2}} \sqrt{\sum_{i=1}^{n}\left(Y_{i}-\bar{Y}\right)^{2}}}
$$

(1) True Vapour Pressure

The true vapour pressure of gasoline at Reid vapour pressure (RVP) is expressed by Antoine equation in Eq. (6), as follows:

$$
\operatorname{In} P=\left(A-\frac{B}{T+460}\right)
$$

where $P=$ true vapour pressure (psi), $T=$ temperature in degree Fahrenheit $\left({ }^{\circ} \mathrm{F}\right), A=1.649$ and $B=1.3225$.

By converting Celsius temperature scale in degree to Fahrenheit $\left({ }^{\circ} \mathrm{F}\right)$ scale and letting $H$ represent the right hand side of Eq. (6a) and solving for $P$, the solution can be as shown in Eqs. (6b) and (6c), respectively.

$$
\exp (\operatorname{In} P)=\exp (H)
$$

$$
P=\exp (H)
$$

\section{Results and Discussion}

In this section, the daily measured values for gasoline emission, dry temperature, wind speed and relative humidity were aggregated into monthly values and presented in Table 1. The percentage gasoline emission in relation to actual sales or demand for each month was examined and presented, also in Table 1. The meteorological data were obtained from a station located in the University of Nigeria at a distance less than one kilometer from the service station. For the period and service station under consideration, the total gasoline vapour emission is $146.4 \mathrm{~L}$. If the emissions of other products such as kerosene and diesel are added, the impact on human around the vicinity may be great. However, a follow up question is, how does the 
Table 1 Monthly emission (V), dry temperature, wind speed, relative humidity and vapour pressure values for the period under consideration.

\begin{tabular}{lllllll}
\hline Month & $\begin{array}{l}\text { Emission } \\
(\mathrm{L})\end{array}$ & $\begin{array}{l}\text { Emission } \\
(\%)\end{array}$ & $\begin{array}{l}\text { Dry Temp. } \\
\text { Avg. }\left({ }^{\circ} \mathrm{C}\right)\end{array}$ & $\begin{array}{l}\text { Wind speed } \\
\text { Avg }(\mathrm{m} / \mathrm{sec})\end{array}$ & $\begin{array}{l}\text { Relative } \\
\text { humidity }(\%)\end{array}$ & $P(\mathrm{psi})$ \\
\hline Aug. 12 & 17.3 & 0.003 & 22.67 & 1.35 & 86.19 & 5.1888 \\
Sept. 12 & 10.7 & 0.004 & 23.22 & 1.02 & 85.10 & 5.1889 \\
Oct. 12 & 5.5 & 0.005 & 22.89 & 0.90 & 80.72 & 5.18888 \\
Nov. 12 & 2.6 & 0.002 & 25.68 & 0.99 & 77.56 & 5.18900 \\
Dec. 12 & 7.4 & 0.005 & 25.54 & 1.20 & 52.01 & 5.18887 \\
Jan. 13 & 10.1 & 0.007 & 23.97 & 1.25 & 50.54 & 5.18893 \\
Feb. 13 & 13.6 & 0.003 & 19.70 & 1.37 & 56.26 & 5.18874 \\
Mar. 13 & 21 & 0.003 & 0.70 & 1.44 & 40.78 & 5.18784 \\
Apr. 13 & 16.3 & 0.003 & -26.9 & 1.08 & 13.77 & 5.18628 \\
May. 13 & 13.3 & 0.003 & -9.76 & 1.00 & 34.72 & 5.18729 \\
Jun. 13 & 14.6 & 0.003 & 8.34 & 1.33 & 57.50 & 5.18822 \\
Jul. 13 & 18.3 & 0.004 & 2.74 & 1.22 & 56.27 & 5.18795 \\
\hline
\end{tabular}

emission value change with these ambient variables?

In this study, the available data were used to verify a trend in order to provide a numerical description for an accurate answer to the above inquiry. However, a scatter plot of the vapour emission and ambient temperature shows that both are correlated as shown in Fig. 1. From the two measures of association namely, covariance and coefficient of correlation, the strength of association between the numerical variables was verified. The plot of wind speed against gasoline vapour emission in Fig 2 shows a direct relationship between the two variables.

In Fig. 3, the gasoline emission maintains a declining linear function with RVP.

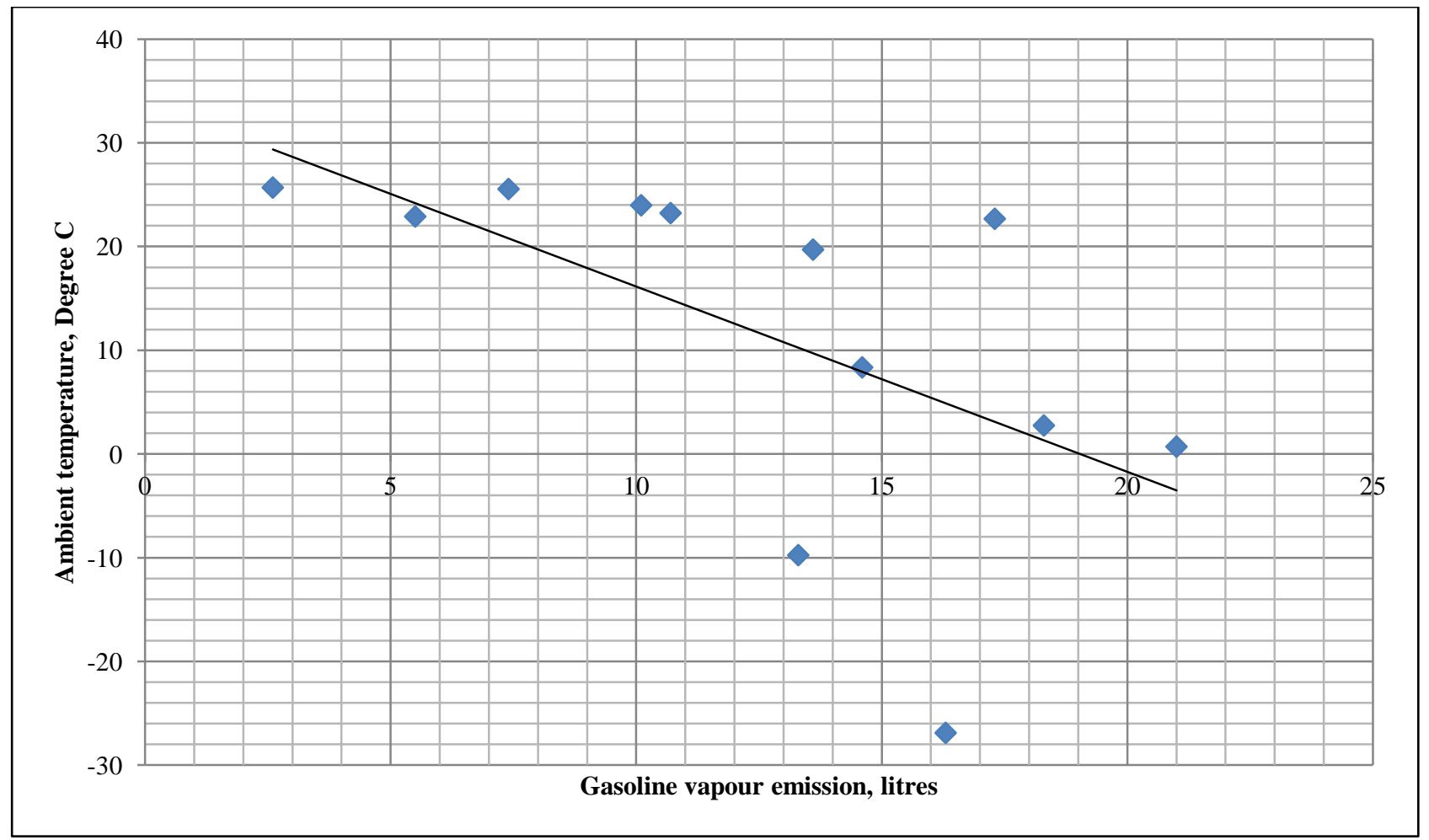

Fig. 1 A plot of ambient temperature $\left({ }^{\circ} \mathrm{C}\right)$ and gasoline vapour emission $(\mathrm{L})$. 

Distribution: Focus on Correlation with Temperature and Wind Variations

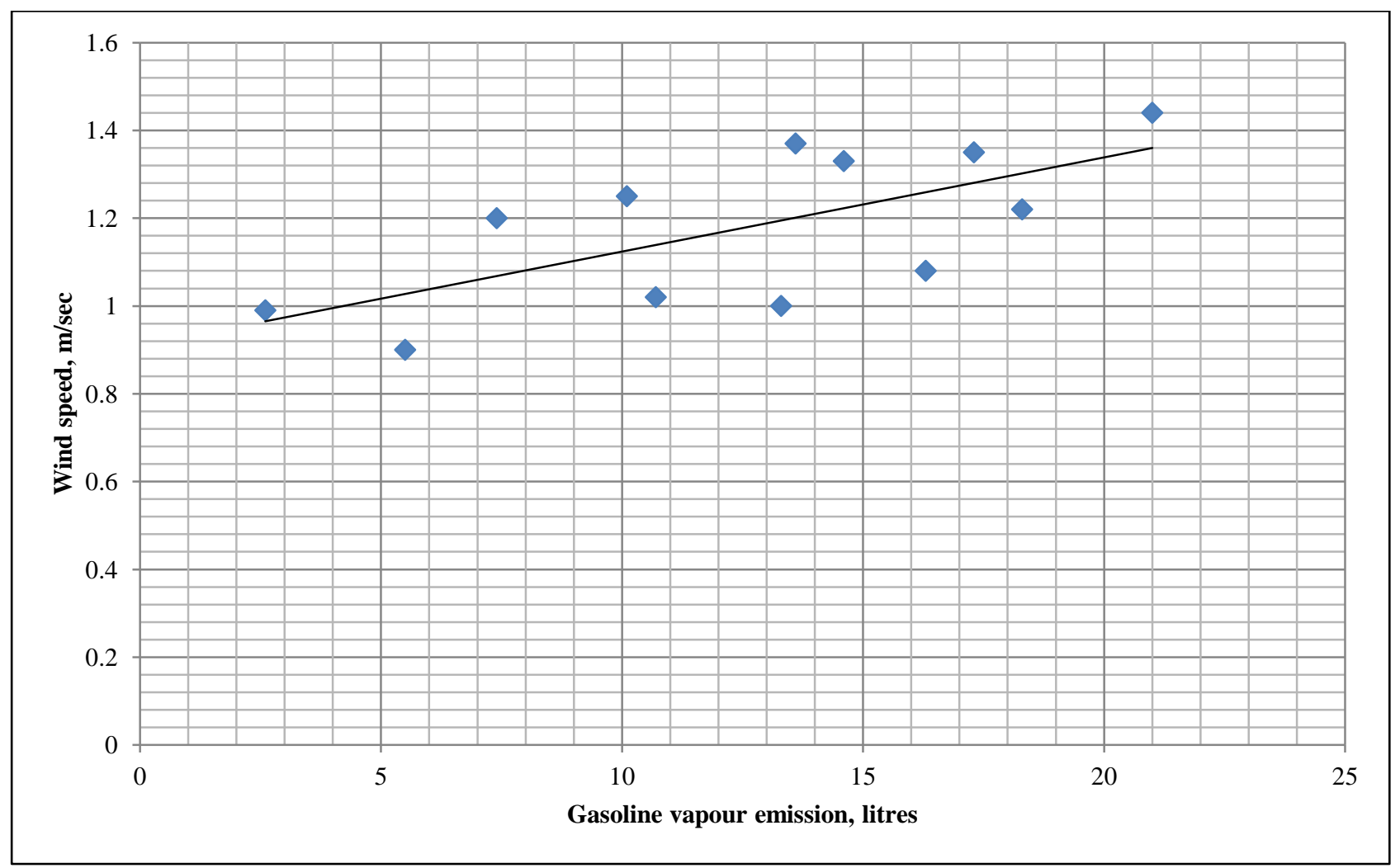

Fig. 2 A plot of wind speed against gasoline vapour emission.

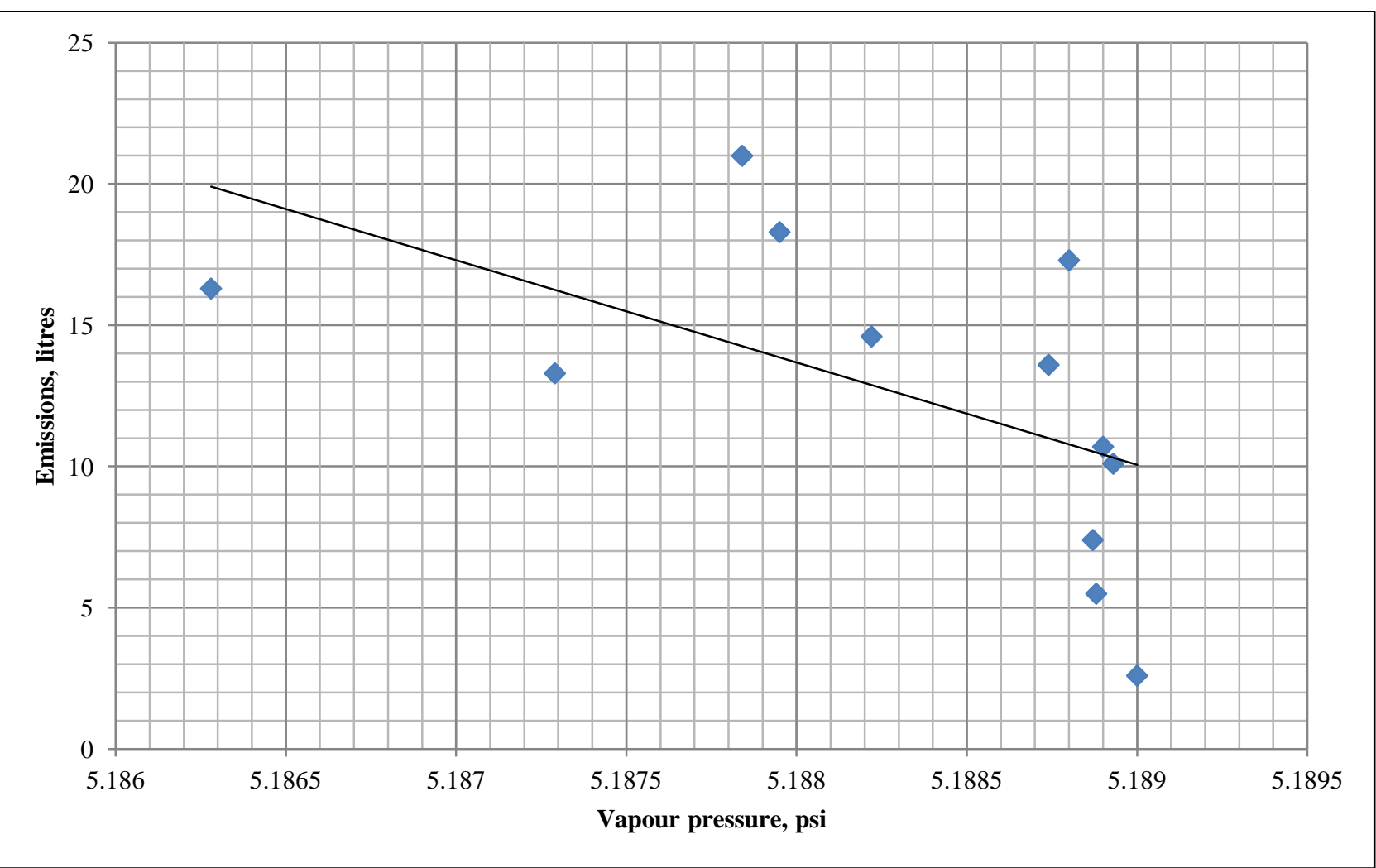

Fig. 3 Gasoline emission (L) against vapour pressure (psi). 
The graphical presentations did not say much about the strength of relationship between the emission and ambient parameters. So the correlation coefficients were calculated and the results show that vapour emission is positively correlated to wind speed and negatively correlated to ambient temperature, with $r$ being equal to 1.0 and -1.0 , respectively.

\section{Discussion}

The relationship between gasoline delivery emission and ambient variables gives a linear response. An evaluation of the monthly wind speeds indicates that they are predominantly between the ranges of 4-6 knots (1.6-3.3 $\mathrm{m} / \mathrm{s})$ which is within light breeze limits. However, petrol vapour is heavier than air and does not disperse easily in still air conditions [12]. Thus, high concentration of emitted gasoline on a hot day constitutes a potential thermal mass high in embodied energy, and if excited by wind speed, can flow many distances away from the station. According to Nwanya [13], the light wind speed could force the vapour emissions far into the surroundings around the filling station environs. The ambient temperature around the station is within a room temperature range as such the effects of the emission on human body may not be physically evident. An exposure to outdoor pollution index value is expressed as a ratio in percentage (\%) of emission to actual demand or sales. Although the value is insignificant for one filling station as shown in Table 1 , when aggregated for a cluster of stations and in relation to the rapid rate at which the number of stations is increasing, there remains a worrisome environmental concern from distribution and storage of energy commodity in Nigeria. Two interpretations can be drawn from the preceding statement. The ever-increasing number of filling stations is an indication of wanton consumption of gasoline. Also, the ratio can stand as an emission factor at the station and it can be used to determine the allowable emission at a given facility/station. From literature, gasoline contains elements of benzene which has been alleged to cause cancer and other carsogenic effects. Moreover, higher concentrations of benzene are more affected by ambient water vapour [14] and the major source of benzene in cities is gasoline, as it is one of its components as well as a product of its combustion [15]. Having noted the nexus between pollutant (filling station emission) and ambient variables, next consideration is the control, with understanding that a gasoline station deals on products in which elimination or reduction of the effects can be by change of attitude and regulatory policy. To this end, Department of Petroleum Resources (DPR) is a leading regulator in oil and gas sector and, through the Petroleum Act (Amendment Decree No. 37 of 1977 Safety Rules And Regulations), has provided suitability inspection guidelines for approval of a filling station site. By evaluating the findings in this study from regulatory perspective, it is obvious that some flaws were revealed in those guidelines for approval to construct and operate a filling station in Nigeria.

\subsection{The Way Forward and Nigeria's Future Volatile Organic Compound VOC Policy Recommendation for Promotion of Eco-Friendly City}

Since the late 1970s, DPR has initiated and created guidelines for approval to construct and operate a filling station site. To underscore the importance of product volatility which a filling station manages, three broad classes were stipulated by DPR on basis of product flash point. They are namely class A, petroleum products (PPs) liquids which have flash point below $21^{\circ} \mathrm{C}$ (e.g. PMS); class B, PPs which have a flash point from $21{ }^{\circ} \mathrm{C}$ to $55{ }^{\circ} \mathrm{C}$ inclusive (e.g. DPK, HHK, ATK); and class C, PPs which have a flash point above $55^{\circ} \mathrm{C}$ up to and including $100{ }^{\circ} \mathrm{C}$ (e.g. AGO) [16]. So far, the policy has achieved some success as a minimum requirement for the reduction of air pollution and its social cost. On the suitability inspection section, a clause only provides for DPR guided/supervised environmental impact assessment (EIA) study of the site by DPR accredited consultant [16]. This section is 
deficient on weather conditions benchmark indices as an EIA decision support tool. Following the revelation from this study that ambient properties have influence on distribution and storage of petroleum products, the above mentioned section is inconclusive. There is a need to make it more inclusive in terms of incorporating atmospheric variables' contribution to vapour emission loss on EIA policy. The essence is to attain the benefits of zero emission of air pollutants and air quality goals. According to Shin [17], zero-emission of air pollutants and greenhouse gas are new social demands which must drive future policy and government regulation. The EIA document in its current form is vague on the influence of ambient properties about hazardous emissions such as VOC. It was to this end that the discourse on future VOC policy for promotion of eco-friendly city initiative is a necessity. The discourse could not have arisen at a better time than now when campaign for clean energy is on the public domain.

With the growing demand for clean energy, decline in the use of gasoline station can be expected, as a result of vapour emission and associated outdoor pollution, in favour of fuel cell and battery as they gain popularity among developing countries as alternate forms of energy storage devices. Since the delivery vapour emission is a management problem, a contrary measure against the anticipated decline will be to implement a stricter rule on VOC emission. This strategy provides the way forward which will promote future eco-friendly city initiative. Thus, eco-friendly city initiative does not require creation of its own new world, but a new order and policy-will towards ensuring synergy between energy activities and development goals without compromise to both aspirations. Another issue is that the filling station managers should engage in as risks preventive measure in the anticipated future city is to recruit professionals as operators. There is a solution to frequent filling station inferno and it comes from training of operators of the filling station. Training will help reduce as well as emissions and the environment will be better for it. With better synergy between urban planners, risk disaster managers (such as National Emergency Management Agency, NEMA) and strict adherence to safety rules Nigerian cities will experience less disaster from filling station operations. In addition, this study advocates for a device that can create a balance between delivery loss sources and possible sinks of emitted products (for example, carbon sink) at the station, having in mind the safety rules, volatile nature of gasoline and climate change implications of its cumulative emissions. According to Matthews et al. [18], as emissions increase, carbon sinks also become less effective at removing $\mathrm{CO}_{2}$ from the atmosphere, which results in a higher airborne fraction of emitted $\mathrm{CO}_{2}$ remaining in the atmosphere. For completeness, the information contained in this section is therefore valuable, if implemented, can guarantee a conducive and friendly environment for the continued operation of filling stations in a city.

\section{Conclusion}

The effects of atmospheric properties on gasoline vapour emission during delivery to end customer have been investigated. The method of direct measurement of the stock withdrawals from underground storage tank was adopted in order to determine vapour emissions. Then, the recorded emission values were correlated with meteorological data. As a consequence, gasoline emission at filling station is an outdoor air pollution factor. The findings from this study suggest that gasoline evaporation loss when fuel is delivered to customers is strongly related to ambient temperature and wind speed variations, respectively. The degree of association of vapour emission with atmospheric parameter was verified by coefficient of correlation index. Although, the index does not represent cause-effect relationship, it showed that both vapour emission and atmospheric variable are strongly correlated. The average emission factor obtained from the study will be useful to environmentalists and policy 
makers within the industry category. To implement the findings for the conservation of the environment, a number of suggestions were made to the government. These suggestions were made with the aim of strengthening DPR guidelines on selection and approval of filling station sites. Notwithstanding the correlation result, further research is warranted to expound the causal relationship between ambient parameters and gasoline evaporation during delivery to end customers. Also, this paper advocates for measures to protect the identified groups of people and entities at risk of pollution from gasoline vapour emission. This study has proven that changes in weather parameters do affect emission rate and this knowledge can affect policy changes.

\section{Acknowledgment}

The authors express their gratitude to those who contributed data and anonymously reviewed the manuscript.

\section{Funding Statement}

This research did not receive any specific grant from funding agencies in the public, commercial, or not-for-profit sectors.

\section{Conflict of Interest}

The authors declare no conflict of interest.

\section{References}

[1] Hilpert, M., Mora, B. A., Ni, J., Rule, A. M., and Nachman, K. E. 2015. "Hydrocarbon Release during Fuel Storage and Transfer at Gas Stations: Environmental and Health Effects." Curr Envir Health Rpt 2: 412-22. doi:10.1007/s40572-015-0074-8.

[2] Eke, M. N., and Enibe, S. O. 2007. "Optimal Scheduling of Petroleum Products Distribution in Nigeria." Nigerian Journal of Technology 26 (1).

[3] Ehinomen, C., and Adeleke, A. 2012. "An Assessment of the Distribution of Petroleum Products in Nigeria." E3 Journal of Business Management and Economics 3 (6): 232-41.

[4] Onyeizugbe, C. U., Orogbu, O. L., Onyilofor, T. U., and Ugbomhe, U. O. 2018. "Business Development and
Sustainability of Selected Petrol Stations in Anambra State of Nigeria." Afr. J. Bus. Mgt. 12 (1): 11-20 doi:10.5897/AJBM2017.8456.

[5] Mshelia, A. M., Abdullahi, J., and Dawha, E. D. 2015. "Environmental Effects of Petrol Stations at Close Proximities to Residential Buildings in Maiduguri and Jere, Borno State, Nigeria." IOSR Journal of Humanities and Social Science 20: 1-8.

[6] Ogunkoya, O. O. 2016. "Urban Planning, Downstream Petroleum Industry and Human Health." Ife Journal of Science 18 (4): 963-71.

[7] Nwanya, S. C., Mgbemene, C. A., Ezeoke, C. C., and Iloeje, O. C. 2018. "Total Cost of Risk for Privatized Electric Power Generation under Pipeline Vandalism." Heliyon 4 (7). doi:10.1016/j.heliyon.2018.e00702.

[8] Belvederesi, C., Thompson, M. S., and Komers, P. E. 2018. "Statistical Analysis of Environmental Consequences of Hazardous Liquid Pipeline Accidents." Heliyon 4 (11). doi:10.1016/j.heliyon.2018.e00901.

[9] The New York Times. 1988. "Gasoline Evaporation Termed a Pollution Factor.” Accessed Sept. 29, 2018. https://www.nytimes.com/1988/05/.../gasoline-evaporatio n-termed-a-pollution-factor.ht.

[10] Abdelmajeed, M. A., Onsa, M. H., and Rabah, A. A. 2009. "Management of Evaporation Losses of Gasoline's Storage Tanks." Sudan Engineering Society Journal 55 (52).

[11] Hoek, G. 2017. "Methods for Assessing Long-Term Exposures to Outdoor Air Pollutants." Curr. Envir. Health Report 4: 450-62. doi:110.1007/s40572-017-0169-5.

[12] Health and Safety Executive, HSE. 1990. Petrol Filling Stations: Construction and Operation. Health and Safety Series Booklet HS (G) 41, p. 5.

[13] Nwanya, S. C. 2011. "Climate Change and Energy Implications of Gas Flaring for Nigeria." International Journal of Low-Carbon Technologies 6: 193-9. doi:10.1093/ijlct/ctr007.

[14] Romero-Trigueros, C., Miñarro, M. D., Duperón, E. G., and Ferradás, E. G. 2017. "Influence of Sample Temperature and Environmental Humidity on Measurements of Benzene in Ambient Air by Transportable GC-PID." Atmos. Meas. Tech. 10: 4013-22. https://doi.org/10.5194/amt-10-4013-2017.

[15] Von Schneidemesser, E., Monks, P. S., and Plass-Duelmer, C. 2010. "Global Comparison of VOC and CO Observations in Urban Areas." Atmos. Environ. 44: 5053-64. https://doi.org/10.1016/j.atmosenv.2010.09.010, 2010.

[16] Department of Petroleum Resources, DPR. 2009. Guidelines for Approval to Construct and Operate a Filling Station. Department of Petroleum Resources, Federal Ministry of Energy, Nigeria. 

Distribution: Focus on Correlation with Temperature and Wind Variations

[17] Shin, W. S. 2017. "Korea's Future Policy Recommendation for the Promotion of Eco-Friendly Vehicles in Metropolitan Area." Journal of Energy and Power Engineering 11: 385-92. doi:10.17265/1934-89752017.06.004.
[18] Matthews, H. D., Zickfeld, K., Knutti, R., and Allen, M. R. 2018. "Focus on Cumulative Emissions, Global Carbon Budgets and the Implications for Climate Mitigation Targets." Environ. Res. Lett. 13: 1-8. https://doi.org/10.1088/1748-9326/aa98c9. 